\title{
UN PUERTO MADERERO EN EL SUR DE CHILE. ANCUD EN LOS AÑOS CINCUENTA DEL SIGLO XIX
}

DIEGO A. MORALES BARRIENTOSa

\section{RESUMEN}

El siguiente artículo analiza la actividad mercantil consolidada en el puerto de Ancud durante la década de 1850, que es cuando experimentó un inusitado incremento de sus exportaciones madereras. Se propone que en dicho escenario se consolidó un grupo limitado de altos comerciantes en la provincia, por lo que se busca seguir sus trayectorias a través de un examen de registros de la Aduana de Chiloé y el Ministerio de Marina de la época. Con ellos se ha podido reconocer sus actividades y las redes comerciales en que participaron. ${ }^{1}$

PALABRAS CLAVE: Exportación, madera nativa, Puerto de Ancud, comerciantes.

\section{A TIMBER PORT IN SOUTHERN CHILE. ANCUD IN THE 1850s}

\begin{abstract}
The article discusses the consolidated commercial activity in the port of Ancud in the 1850, when this activity unexpectedly increased. We propose that this situation helped in the consolidation of a limited group of important traders at the province. For this reason their trajectory was followed by studying the records of the Chiloé customs and the Ministerio de Marina. Their activities and commercial networks were identified.
\end{abstract}

KEY WORDS: Export, native wood, Ancud port, local traders.

a Estudiante del Programa de Doctorado en Historia de la Universidad de Santiago de Chile. Becario CONICYT. diegobtos@ gmail.com

1 Este trabajo ha sido auspiciado por el Proyecto 149801. "Hacia una cultura de indicadores de desempeño en la Universidad de Santiago de Chile", Facultad de Humanidades USACH. Además, han sido de utilidad los comentarios críticos de los doctores Juan Guillermo Muñoz y Hernán Venegas Valdebenito. 


\section{INTRODUCCIÓN}

La ciudad de Ancud fue fundada como emplazamiento militar en una época tardía del período colonial cuando el imperio español impulsó una reorganización de la plaza de Chacao para renovar en Chiloé un punto estratégico y periférico de la monarquía en América (Urbina, 1983). Sin embargo el componente militar de la ciudad fue declinando en el siglo XIX, con lo cual los fuertes de Agüi y San Carlos (Fischer, 1987) se batieron en retirada e incidieron cada vez en forma más limitada en su paisaje, donde comenzaron a visibilizarse la catedral, un mercado de abasto, bodegas, almacenes y los diversos muelles privados que articularon el creciente tráfico marítimocomercial del conjunto del archipiélago.

En la década de 1850 Ancud era el principal núcleo urbano de la provincia y como tal llegó a concentrar buena parte de los flujos de la madera nativa que circularon en toda la región, gracias a que allí se radicaron los más "altos" comerciantes del archipiélago. Desde su bahía importantes mercaderes colocaron en juego sus propios recursos, influencias y conocimientos acopiando la madera que abastece los barcos llegados desde los distintos puertos del país y Perú. En el seno de este flujo nos interesa profundizar sobre las dinámicas desarrolladas en el puerto y en particular explorar el comportamiento y alcance de las redes comerciales creadas por quienes tomaron un papel protagónico en el negocio maderero chilote, determinando las razones de por qué el mercadeo se fue desplazando desde Ancud a los puntos de embarque situados en Llanquihue.

Según observamos, un grupo reducido y cerrado de comerciantes capturaron para su propio beneficio la exportación de maderas nativas, consolidando su posición de prestigio y reconocimiento en el conjunto del archipiélago. Unidos por enlaces matrimoniales, comerciantes prominentes del archipiélago desarrollaron instalaciones portuarias y mantuvieron sus propias embarcaciones, estructurando redes comerciales relativamente estables en el interior de Chiloé y con el resto de los puertos del país. Pese a ello, estas redes ni los intercambios que dieron origen alcanzaron a transformar los rasgos tradicionales del trabajo realizado por los hacheros en la elaboración de la madera o el paisaje rural predominante en la ciudad-puerto, ya que, como grandes mercaderes, se desentendieron de los puntos de explotación ubicados en los diferentes "nudos" forestales de la región. Por lo mismo los miembros del alto comercio local se mostraron débiles para competir en el mediano y largo plazo con los aserraderos mejor provistos que comenzaron a desarrollarse en Llanquihue y otros puntos de explotación, lo que desencadenó el parcial declive de la actividad portuaria y exportadora de Ancud al deteriorarse su posición articuladora del tráfico marítimo maderero al término de la década de 1860.

En relación a la actividad económica de la provincia de Chiloé decimonónico no abundan los trabajos que permitan dilucidar cuáles fueron sus rasgos más sobresalientes aun cuando predomina una imagen afincada en la continuidad colonial y un inamovible tradicionalismo productivo (León, 2004). A ello se ha sumado un reconocimiento del dinamismo comercial sobre todo de la ciudad de Ancud a raíz de la exportación de tablas (Moraga, 1992) y se ha buscado en eso una explicación para el incremento en el número de tiendas y baratillos a fines de la década de 1870 (León, 2004). El problema central y a su vez el desafío que instalan estos escasos estudios sobre la vida económica chilota es avanzar en el reconocimiento de sus actores específicos, para establecer desde ellos el comportamiento generalizado de la región.

Atendiendoa esa preocupación parecenútiles las discusiones surgidas en el seno de los estudios de la historia rural y agraria (Fradkin, 2006, pp. 192-3) para efecto de elaborar una aproximación contextualizada del mundo social y económico de Chiloé en el siglo XIX. En particular, porque dichos estudios recuperan no solo la necesidad de realizar un trabajo documental imprescindible para el trabajo historiográfico ("volver a las fuentes"), sino que también consideran un examen detenido de las estructuras operantes, contemplando los rasgos y atributos socio-económicos de los sectores predominantes, el seguimiento de "empresas" específicas y las tradiciones o pautas culturales existentes. Atenta de los espacios, las relaciones sociales y de la producción, desarrolla un enfoque a nivel micro que no rehúye del análisis del conflicto, las desigualdades y de los sistemas de disciplinamiento 
o encuadre social, que en ocasiones se omite del mundo agrario al prevalecer un análisis detenido de la producción en sus dimensiones generales o agregadas (Garavaglia \& Gelman, 1998).

Los lineamientos de esa historiografía suponen una mirada fructífera para el análisis de la región chilota, especialmente por la persistencia en el siglo XIX de sus particulares estructuras de poblamiento (ribereño), insularidad (con dispersión geográfica) y cultura (impregnada de una impronta indígena), que en muchos aspectos se presenta incomprensible en modelos interpretativos aplicables en las regiones centrales del país, donde la gran propiedad y el acervo cultural de las haciendas dieciochescas incidieron en su articulación social, económica, política y cultural. Al contrario de dicha configuración, entendiendo que el archipiélago presenta algunos aspectos de territorio fronterizo, cabe encontrar sus propios patrones de cambio, dinamismo, funcionamiento $y$ conflicto, para lo cual precisamente, exploramos a continuación uno de sus ejes centrales: la activación de una élite volcada fundamentalmente al comercio durante la década de 1850, la cual constituyó en relación a sus propias dimensiones, una suerte de alto comercio para el conjunto del archipiélago.

Para ello se ha consultado en dependencias del Archivo Nacional Histórico (ANH) el Fondo del Ministerio de Marina, que contiene documentación surgida de la Gobernación Marítima de Chiloé creada con sede en Ancud en 1848. Esta oficina registró las diversas incidencias del acontecer marítimo de la región y en particular de la actividad portuaria de la capital provincial, sirviéndonos para levantar información sobre el tráfico portuario y los problemas que el gobernador, Miguel Hurtado Guerrero, tuvo para gestionar la bahía con ocasión del incremento del comercio maderero de bahía de Ancud. También se ha consultado el Fondo Aduana y Tesorería de Chiloé concerniente a toda la década de 1850 y hasta 1864. En este caso se realizó un examen con profundidad en los años 1855 y 1858 para representar al conjunto de la época, vaciándose en una planilla toda la información concerniente a la importación y exportación registrada por la institución, la cual ha sido procesada para realizar un seguimiento específico tanto de los barcos como de las sociedades comerciales ocupadas en la exportación de maderas, dejándose para otra comunicación un estudio detenido y exclusivo de los volúmenes y precios alcanzados por dicho recurso. Por otra parte, se ha explorado el Fondo Intendencia de Chiloé y fragmentos del Fondo Ministerio del Interior, para ampliar el análisis y las trayectorias de los miembros del alto comercio chilote, lo cual en último término se ha nutrido de la revisión de periódicos como El Chilote (1868) y El Imparcial (1885), quienes observaron con preocupación cómo el archipiélago iba perdiendo influencia comercial en la región insular con los años.

Con todo, a través de la revisión de los fondos documentales aludidos se ha buscado retrotraer una primera aproximación histórica a las élites de la región entendiendo que como grupo más bien informal (Guerra, 2000, p. 119) pero claramente diferenciado de los sectores indígenas y campesinos, asumieron un papel activo de la exportación. Fue ese selecto grupo el que movilizó sus propios medios para la habilitación de los trabajadores locales y transportar las maderas nativas por los canales interiores de la provincia, perfilándose económicamente como un grupo volcado hacia la actividad comercial. Un argumento que se desarrolla en cuatro apartados distintos: el primero analiza el tráfico portuario de Ancud colocando énfasis en el incremento de la demanda extra-regional; el segundo caracteriza el funcionamiento y regulación de su actividad portuaria estableciendo sus principales problemas así como las alternativas que ofrecía al pequeño mercadeo de productos locales; el tercero, nudo central del artículo, precisa quiénes y en qué proporciones participaron los principales miembros del comercio maderero local; el cuarto, busca establecer las relaciones y redes familiares entre algunos de los comerciantes más destacados. Al momento de concluir se abordan algunas hipótesis y problemas planteados en general por el estudio.

\section{DINAMISMO PORTUARIO DE ANCUD}

En los años cincuenta del siglo XIX la economía nacional experimentó una expansión como respuesta al mayor dinamismo de las exportaciones derivadas de la actividad minera y agrícola (Ortega, 2005). En ese proceso la provincia 
Tabla 1. Ingreso embarcaciones Puerto Ancud.

\begin{tabular}{cccccccccccccc}
\hline & Enero & Febrero & Marzo & Abril & Mayo & Junio & Julio & Agosto & Sep. & Oct. & Nov. & Dic. & Total \\
\hline 1855 & 9 & 12 & 11 & 11 & 10 & 10 & 8 & 8 & 10 & 9 & 10 & 20 & 128 \\
1857 & 12 & --- & 12 & 15 & 8 & 4 & --- & 7 & 10 & 16 & 13 & 14 & 111 \\
1858 & 16 & 14 & 17 & 14 & 16 & 8 & 7 & 14 & 11 & 11 & 12 & 8 & 148 \\
1859 & 21 & 19 & 14 & --- & 6 & --- & --- & --- & 10 & 10 & 6 & --- & 86 \\
1860 & 13 & 11 & 18 & 11 & 9 & 6 & 8 & 10 & 9 & --- & -- & --- & 95 \\
1863 & 11 & 8 & 12 & 11 & 9 & 7 & 6 & 10 & 6 & 10 & 14 & 11 & 115 \\
\hline
\end{tabular}

Fuente: Ministerio de Marina, vols. 157, 159, 160.

de Chiloé participó pero en un nivel secundario, porque además de su distancia geográfica no era reconocida como un área rica ni propicia para la producción de cereales, aunque sí poseedora de vastas extensiones de bosque nativo. Un recurso extremadamente necesario que desde el puerto de Ancud se proveyó de manera eficaz al surtirse de tablas, tablones y durmientes de alerce, ciprés o roble al conjunto del mercado nacional (Moraga, 1992; León, 2004).

La extracción de madera en Chiloé era una tradición arraigada entre las actividades económicas de la población desde la época colonial cuando las tablas de alerce formaron parte preferente de los envíos al Virreinato de Perú. Los barcos peruanos visitaron continuamente Chacao en el siglo XVII y San Carlos de Ancud en la segunda mitad del siglo XVIII, cambiando artículos elaborados localmente como maderas, ponchos, jamones y pescados ahumados por paños de Castilla, i bayetas, paños de Quito i ropa de la tierra, vino, aguardiente, sal, aji, listonería, Bretaña i todo lo demas, tal cual lo registró en su Relacion jeográfica Cárlos de Beranger en 1773 (1893, p. 45). Este intercambio, ha establecido Rodolfo Urbina, originaba ferias donde el valor pagado por los artículos importados recibían un sobre precio superior al 40\% (Urbina, 2009 , p.74) dado que además de sumarse el valor del traslado y los impuestos pagados en Lima, se agregaba el habitual regateo de los capitanes de barco, quienes eran implacables en la búsqueda de disminuir los precios de los artículos locales afectando negativamente la producción isleña.

Los escasos cambios producidos en la sociedad chilota indican que el intercambio desigual de la época colonial redituó al comercio peruano pero redujo invariablemente las posibilidades de la región para beneficiarse de la exportación de sus recursos, algo que tampoco sucedió durante el auge exportador de mediados del siglo XIX, aun cuando el negocio maderero alcanzó dimensiones superlativas determinando que la degradación más importante de los bosques de la región ocurrió en realidad (...) en tiempos de la República (Torrejón et al. 2011, p. 77) y no mientras el control económico estuvo en manos peninsulares. De hecho, si Urbina contabilizaba cerca de diez embarcaciones recaladas anualmente en San Carlos de Ancud durante la década de 1780 y 1790 (2009, p. 68), en 1849 los barcos ingresados desde puertos ajenos a la provincia sumaron 71 y 148 en 1858, punto más alto del movimiento portuario alcanzado entre los años 1855-1863 de acuerdo la Tabla 1.

El registro de las embarcaciones ingresadas al puerto de Ancud muestra que la plaza era un punto de contacto habitual en la navegación entre los diferentes puertos de la costa, y que su dinamismo quedaba inexorablemente ligado al derrotero económico del norte y centro del país. Una parte de los barcos avistados en Chiloé participaba del transporte de minerales cargados en Coquimbo o Caldera y también en el traslado del trigo y la harina que se embarcaba en Valparaíso con destino a California, Estados Unidos. Así, la "Joven Julia" de 250 toneladas en 1850 arribaba a Ancud para cargar madera y tres años más tarde ingresaba a San Francisco (Estados Unidos) con sacos de harina, mientras el barco "Dos Amigos", de regreso a Chile desde California en 1853, arribaba a Ancud en octubre de 1854 cargando maderas para retomar ruta a Caldera, como informan los registros aduaneros de la época.

Un segundo punto para destacar del cuadro 
es que al puerto de Ancud llegaron embarcaciones ocupadas solo marginalmente en el negocio maderero y por lo mismo las cifras incluidas son excesivas para precisar los envíos desde Chiloé a otras regiones. Continuamente recalaron en la bahía barcos pertenecientes a la escuadra naval de Chile -con navegación preferentemente al estrecho de Magallanes- y vapores subvencionados por el Estado en concordancia con la nueva legislación de 1851, que estableció ruta mensual entre Valparaíso, Talcahuano, Corral y Ancud en viajes que los vapores "Nueva Granada", "Talca" o "Cloda" demoraban seis o siete días². Sumado a ellos todos los años ingresaban barcos balleneros de bandera extranjera encontrando un lugar propicio para dirigirse a los litorales insulares de Guaitecas y Chonos (Martinic, 2004, pp. 111-2) o al golfo de Guafo, áreas reconocidas internacionalmente por la abundancia de cetáceos.

Al inicio del siglo XIX en las costas del sur de Chile se avistaban barcos balleneros ingleses pero con el paso de los años fueron disminuyendo su frecuencia en relación a los cada vez más comunes barcos balleneros llegados de Nantucket o New Bedford, estado de Massachusetts en Estados Unidos (Quiroz, 2010, pp. 4-5; Carreño \& Espinoza, 2013, pp. 67-70). Fue el caso de la fragata ballenera "Samer Lane", "María Theresa", "Newton", "Anaconda" y "Atkin Adam" en 1855 y, cinco años más tarde los barcos "Jeneral Like", "Biaganila", "Imgrina" y "Minerva", en que usualmente se transportaba una tripulación de 40 marineros, quienes llegaban a Ancud buscando descanso luego de superar cien o más días de navegación y necesitados de provisiones o en ciertos casos de la reparación de los cascos.

Los barcos militares, balleneros y vapores con ruta mensual a la bahía de Ancud en 1855 fueron 27, reduciendo a 101 los barcos directamente involucrados en el comercio y el transporte de mercaderías y entre ellos no todos

2 De acuerdo a Véliz la navegación a vapor de Valparaíso al Sur fue promovida por altos intereses de la zona, lo cual impulsó al Gobierno a subvencionar "hasta 36.000 pesos a la línea de vapores que estableciera comunicación periódica mensual entre Valparaíso y el Sur del país empleando vapores de un mínimum de 300 toneladas" (1961, p. 118). Según dicho autor, la primera firma naviera favorecida de esa subvención fue Robert Simpson, Nicomedes Osa y Cía. quienes en 1851 se adjudicaron un contrato que cargaron maderas puesto que algunos zarparon en lastre o con sal a Río Bueno y Valdivia. Esto quiere decir que en 1855 no más de 95 embarcaciones trasladaron maderas a distintos puertos de la costa del Pacífico, mientras que el mismo ejercicio en 1858 y 1863 -donde están completos los registros del cuadro $\mathrm{N}^{\circ} 1$ - significa reducir el número de embarcaciones a 97 y 85 respectivamente. Esta precaución de los antecedentes del cuadro $\mathrm{N}^{\circ} 1$, en todo caso no alcanza a alterar el hecho central, que es el notorio incremento de los volúmenes de la madera exportada desde el archipiélago de Chiloé al compararse el número de embarcaciones de la década de 1850 con las décadas finales del siglo XVIII.

Este incremento era resultado de la mayor demanda existente, pero también de la ampliación geográfica de las redes comerciales establecidas por el archipiélago. Durante la época colonial la exportación de maderas se encausó únicamente a Perú, un destino al que siguieron arribando durante todo el siglo XIX, aunque en una proporción menor dado que los barcos con bandera peruana constituyeron el $6 \%$ en 1855 y el $10 \%$ tres años más tarde si se consideran los registros aduaneros. Por ello, tampoco era viable que dichas embarcaciones, aun cuando superaran las 150 toneladas de capacidad y algunas incluso las 300 a la par de los promedios usuales de la época (Garrido et al. 2006, p. 59), lograran abastecer a sus distintos puertos: Callao, Paita, Ilo o Arica. Por lo mismo, durante la década de 1850 la exportación maderera recayó en barcos con bandera "nacional" pese a que eran navegados y tripulados por extranjeros tal como explica Claudio Véliz en su análisis sobre la marina mercante y los cambios de la legislación proteccionista de 1834 y 1836, la que fue erosionada por principios liberales a contar de 1849 y 1850 (Cavieres, 1988, pp. 107-108).

Así, la exportación de madera chilota

habilitaba al vapor "Arauco" para realizar el trayecto, pero quedó rescindido dos años más tarde cuando la embarcación naufragó en la costa de Talcahuano. Frente a ello, en 1853 se aceptó la propuesta de la Compañía de Navegación a Vapor del Pacífico (C.N.V.P.) que inició viaje mensual entre Valparaíso y Ancud pasando por Maule, Tomé, Talcahuano y Corral, a cambio de una subvención que en 1857 se elevó a 50.000 pesos por indicación de Antonio Varas (Véliz 1961, p. 120). 
encontró en Valparaíso y no en el Callao el destino más frecuente de sus envíos, un cambio que parece natural si se toman en cuenta las reformas políticas auspiciadas desde el inicio de la república y su apoyo a la libertad de comercio. Al ser la plaza comercial más importante del país, Valparaíso era el "nudo" del abastecimiento de Santiago y los valles centrales, donde la madera nativa del sur de Chile iba a ser necesaria en las edificaciones urbanas que comenzaban a cambiar el paisaje citadino de la capital, así como de las vías férreas que se fueron extendiendo, las mismas que se visualizaron en el extremo norte del país, como en Caldera o Coquimbo, donde la actividad minera también se transformaba en una continua consumidora de los recursos explotados en los bosques chilotes.

Con Valparaíso, Caldera y Coquimbo existió un tráfico regular de barcos que llegaban en lastre y zarpaban de regreso cargados con maderas luego de permanecer cerca de dos semanas en la bahía, tiempo que demoraba completar la carga de miles de piezas. Una parte de dicho tráfico fue desarrollado por barcos especializados en el transporte de madera como el "Paulina i Catalina" que desde Valparaíso hizo travesía en cinco oportunidades durante 1857, lo cual sucedió también con el "Eclipse" y el "Africano" al arribar en Ancud en tres ocasiones ese mismo año. Por la regularidad de esos viajes es muy probable que esas embarcaciones hayan sido de propiedad de algún comerciante chilote, aunque no nos ha sido posible encontrar la titularidad hasta donde hemos indagado en los registros de Aduana y en el Ministerio de Marina, repartición encargada de matricular a cada embarcación del cabotaje nacional. Mayor fortuna tenemos en relación a la barca "Carmen Dolores" que fue adquirida por uno de los principales comerciantes chilotes, Juan de Dios Navarro, en octubre de 1855 sirviéndonos para ilustrar con especial detalle su intensa relación comercial y capacidad exportadora al realizar ruta frecuente entre Ancud, Valparaíso y Coquimbo como se desprende del registro de Aduanas de 1857, en que la embarcación zarpó desde Ancud el 11 de enero, 12 de marzo, 5 de mayo, 4 de agosto, 19 de octubre y el 27 de diciembre (jseis viajes en total!), es decir, un viaje completo cada dos meses. Una dinámica que se mantuvo al año siguiente porque su tripulación compuesta por el capitán Rafael González y ocho marineros, zarparon de Ancud con maderas a Coquimbo el 16 de febrero, 3 de mayo y $1^{\circ}$ de agosto, retomando ruta nuevamente a Valparaíso el 26 de octubre de ese año.

Para que ese flujo existiera Juan de Dios Navarro necesitó de un contacto directo y permanente con distintas casas comerciales ubicadas en los puertos de origen (Valparaíso o Coquimbo), pues era la seguridad de tener compradores lo que impulsaba a comprar la madera en el interior de la región, acumulando "castillos de tablas" durante todo el año en la bahía de Ancud. Sin ello, era difícil que el negocio maderero se lograra articular porque Navarro y otros comerciantes de la plaza no tenían acceso fácil ni inmediato a núcleos forestales para obtener madera, necesitando transportarla a través de embarcaciones menores o balandras, en circunstancia que era explotada en los bosques de la isla grande, las cordilleras del este y las islas Guaitecas, es decir, lejos del epicentro comercial de Ancud (Urbina, 2011).

Mientras el nexo de los comerciantes chilotes y las casas comerciales fuera sólido no hubo inconvenientes y en la bahía de Ancud se mantuvo un tráfico importante de naves para cargar madera. El dilema es que fue justamente esa certeza la que comenzó a vulnerarse durante la década de 1860 , dado que surgieron otras plazas en la región con capacidad para abastecer madera a un número creciente de barcos. Al compararse los años 1855 y 1858 el tráfico de barcos registrados por la Aduana de Chiloé, se observa con nitidez la progresiva participación de Puerto Montt en la exportación de maderas, puesto que si bien en 1855 únicamente dos embarcaciones mayores zarparon desde Ancud y retornaron al puerto con maderas embarcadas en Llanquihue, tres años más tarde esa cifra aumentó a siete, colocando un antecedente crucial para el posterior declive mercantil de Ancud y la posterior erosión de su papel monopólico como interlocutor de la región chilota en el mercadeo maderero de país.

En efecto, esto no pasó desapercibido para observadores como Alfredo Weber, quien aseguró que el dinamismo de los comerciantes ancuditanos tuvo su base en una ganancia fácil i pasajera (Weber, 1903, p. 40), precisamente, porque 
aprovecharon de manera breve la expansión de la demanda cuando otras localidades aún no tenían suficiente infraestructura ni redes para acaparar y vender grandes cantidades de madera, situación que se alteró con la consolidación de la población de Llanquihue. En ese momento El Chilote miraba con pesar el lento mercadeo y señalaba el 19 de junio de 1868 que el precio de las maderas ha ido bajando gradualmente [...y] la exportación no será mui abundante en el año corriente (p. 3) apuntando que la competencia regional tenía una incidencia sustantiva en esa circunstancia.

\section{LA GESTIÓN Y VIDA MERCANTIL DE LA BAHÍA}

Para el Estado, los puertos y las aduanas fueron espacios propicios para la recaudación fiscal durante la primera mitad del siglo XIX (Cariola \& Sunkel, 1990, pp. 28-9) y aunque Ancud estuvo lejos de ser un punto de verdadero interés para la hacienda pública, como si lo fueron Valparaíso y más adelante Iquique, igualmente fue dotada de funcionarios para que fiscalizaran su movimiento marítimo y comercial. Coincidencia o no, cuando todavía la exportación de maderas no comenzaba su expansión definitiva en 1848, la plaza de Ancud se transformó en cabecera de la Gobernación Marítima de la provincia y se sumó a la Aduana y Tesorería Unida de Chiloé como entidad especializada en el registro, supervisión y organización de la vida económica de sus aguas inmediatas.

La tarea de organizar y supervisar el intercambio de pasajeros y mercaderías estuvo dificultada inicialmente por la gran distancia del muelle al surjidero (Rondizzoni, 1854, p. 23), lo cual impedía que un barco se colocara a borde del muelle -algo que afectaba a todos los puertos del país en la época-. Esto exigió el desplazamiento regular de un oficial y una chalupa de la Aduana para realizar in situ un registro de las características

3 ANH, Fondo Ministerio de Marina, Vol. 140 , "Embarcaciones menores que se ocupan dentro del puerto en el tráfico de él mismo y en otras industrias de mar", $1^{\circ}$ de octubre de 1856 , s./f.

4 Según los registros elevados por el gobernador marítimo, Miguel Hurtado Guerrero, en el listado de "Embarcaciones menores que se ocupan dentro del puerto en el tráfico de él mismo" entre 1856 y 1859, las balandras -entre 20 a y tripulación de cada barco, verificando en la oportunidad la cantidad de "pases libres" en consignación que eran transportados. Si el barco llegaba en lastre, como ocurrió con cerca del $40 \%$ de las embarcaciones ingresadas en 1855 y 1858 , un bote del muelle llevaba a tierra a la tripulación si es que lo autorizaba el capitán del barco. Mientras que, si el barco estaba cargado con equipaje o mercaderías se movilizaba inmediatamente -si el tiempo así lo permitía- una fracción de los 30 botes particulares ${ }^{3}$ y parte de los doscientos hombres que asumían las tareas de carga y descarga en el puerto (Rondizzoni, 1854, p. 24) ${ }^{4}$.

El procedimiento descrito era el estipulado idealmente, pero los oficiales de la Aduana enfrentaron dificultades permanentes para mantener el control adecuado sobre cada barco. Un hecho simple como la botadura de arena -que estaba restringido al sector de Lechagua- o rocas en lastre se constituyó en un problema insalvable para Alfredo Weber pues al despuntar el siglo XX, reconocía en la escasa preocupación de los funcionarios de la Gobernación Marítima la razón por la cual se provocaron cambios en la profundidad de la bahía (Weber, 1903, p. 6) creando acumulaciones artificiales de arena y rocas que perjudicaron para siempre su navegabilidad. También lo había señalado el doctor Johann Jakob Von Tschudi cuando en viaje desde Francia y con destino a Perú, en 1838, censurara el actuar negligente de los empleados de la Aduana en el resguardo de las actividades comerciales y marítimas, así como las deficientes instalaciones y recursos con los que contaban, según observó durante su estadía en las costas inmediatas a Ancud (Von Tschudi, 1842, p. 8).

Para 1850 la Aduana contaba con un servicio de ocho miembros y cinco años más tarde sus siete empleados eran asistidos por un personal en terreno desplegados en los distintos puntos de la bahía. Tomó vida propia el resguardillo de Balcacura que a la sazón era un antiguo emplazamiento militar, pero rápidamente transformado en uno de

40 toneladas promedio- ocupadas en la bahía de Ancud bordearon las cincuenta, mientras que en la misma fecha se habían matriculado al menos treinta botes o lanchas y cerca de diez chalupas que con tripulaciones de seis a ocho marineros tenían una capacidad de transporte no mayor a ocho toneladas. A modo de ejemplo, Véase: ANH, Fondo Ministerio de Marina, Vol. 148, $1^{\circ}$ de febrero de 1857 , s./f. 
los puntos estratégicos para la regulación del tráfico marítimo pues allí se puede ver con la vista natural las operaciones de los buques favoreciendo el atajo de la defraudación de las rentas fiscales, porque vigilando tan de cerca a los buques no les será á éstos fácil hacer desembarcos clandestinos $^{5}$. Considerando esa potencialidad, que se ubicaba frente al muelle fiscal y era un sitio protegido de los vientos, en el verano de 1855 la Aduana edificó allí una casa licitada a favor de Juan de Dios Navarro, de modo que constructores locales levantaron una obra de veinte varas de largo, ocho de ancho y tres $i$ media de alto con corredores, cinco puertas y cuatro ventanas con cerraduras, que tuvo un costo total de $\$ 1.735,35^{6}$. Inmediatamente se radicó un servicio de vigilancia compuesto por trece empleados -un comandante, dos tenientes, tres guardas, un patrón (de lancha) y seis marineros- pero ampliado en el mes de octubre a 18 miembros, de acuerdo con el detalle de las planillas salariales donde cobraban mensualmente un comandante, dos tenientes, seis guardas, dos patrones y nueve marineros ${ }^{7}$.

Como es natural la readecuación de Balcacura no fue la única obra emprendida para facilitar la gestión marítima en respuesta al incremento de la actividad portuaria. A ella se puede agregar la construcción del Faro Corona en 1859 -Valparaíso tuvo faro operativo en 1838 (Véliz, 1961)-, la ampliación del edificio de la Aduana y las reparaciones anuales realizadas a las chalupas utilizadas por la institución. Estas obras a nivel local beneficiaron con jornales directos a maestros, carpinteros y albañiles, quienes con toda seguridad tuvieron mayores opciones para ocuparse en la década de 1850 que en la década inmediatamente anterior, al encontrar además nuevas opciones de trabajo en las obras realizadas por los miembros más destacados del comercio al mejorar o habilitar sus propios muelles y bodegas en puntos no muy lejanos al muelle fiscal como Quetalmahue, Lechagua, Balcacura, Agüi, el dique, Punta Arenas y la desembocadura del río Pudeto.

La dispersión de los muelles existentes repercutió negativamente en las labores de

5 ANH, Fondo Ministerio de Marina, Vol. 140, $1^{\circ}$ de octubre d e1856, s./f.

6 ANH, Fondo Aduana de Chiloé, Vol. 84, leg. 2, doc. 77, 18 de febrero de 1855 , s./f supervisión llevadas a cabo por los miembros de la Aduana o la Gobernación Marítima. Las tareas administrativas en el caso de los barcos arribados en lastre eran relativamente simples en comparación con aquellos que ingresaban con barriles, cajas, sacos, fardos, atados y baúles, donde era preciso un oficial en la descarga para establecer los valores de la recaudación fiscal. Con esa preocupación, un empleado aduanero, el 15 de octubre de 1858 reaccionó con sorpresa por la curiosa explicación del capitán del barco peruano "Rosalia Mosso", quien pese a tener mercaderías extranjeras declaró no tener intencion de dejarlas en el puerto, obligándolo por la sospechosa declaración a fondear frente al resguardillo, para vijilarlo debidamente durante la noche ${ }^{8}$. En efecto, el contrabando como indicara el trabajo canónico de Sergio Villalobos (1968) sobre la introducción ilegal de mercaderías inglesas en la gobernación de Chile con anterioridad a la Independencia, era una materia recurrente en las actividades comerciales de los puertos y en Ancud esa realidad estuvo favorecida tanto por la cantidad de puertos privados como por el intenso tráfico de la bahía.

Situaciones como la expresada con el barco "Rosalia Mosso" era algo difícil de controlar cuando en una misma semana o mes se reunían con facilidad hasta veinte embarcaciones de tonelaje mayor, que se suman a las decenas de balandras que surcaban habitualmente entre Ancud y distintos puntos del archipiélago. Si bien algunos barcos llegaban a completar víveres y zarpaban rápidamente como lo hicieron la mayor parte de los barcos balleneros norteamericanos, era habitual que una nave se mantuviera quince o más días en las proximidades del puerto. El "José Guimaraens", por ejemplo, en 1859 ingresó en tres oportunidades a Ancud (marzo, agosto y octubre) realizando ruta Valparaíso-Ancud-Puerto Montt. El arribo a la bahía de su primer viaje se produjo el 2 de marzo pero recién el 11 de ese mes retomó su trayecto hacia Puerto Montt de donde regresó con maderas y dos pasajeros el 2 de abril, sumando más de treinta días en las inmediaciones de la ciudad antes de retornar al norte hacia Coquimbo el 6 del

\footnotetext{
ANH, Fondo Aduana de Chiloé, Vol. 86, leg. 2, doc. 48, 31 de octubre de 1855, s./f.

ANH, Fondo Aduana de Chiloé, Caja 4, leg. 1, doc. 30, 15 de octubre de $1858 \mathrm{~s} . / \mathrm{f}$.
} 
mismo mes. Asimismo, el "Concepción", de 199 toneladas, ingresó el $1^{\circ}$ de octubre de 1857 con viaje desde Caldera y tomó curso a Cobija cargado de maderas solo el 30 de ese mes, es decir, estuvo justo un mes en las inmediaciones de la bahía de Ancud?.

Esto indica que la tecnología portuaria de la época, las exigencias burocráticas de supervisión y registro así como la dispersión de los muelles y puertos determinaron que un barco se mantuviera en Ancud un tiempo prudente $y$ prolongado, alcanzando una estadía usual de dos semanas. Tiempo más que suficiente para que se emprendieran los trabajos de descarga que estaban sometidas a los cambios en el tiempo y marea, la disponibilidad de oficiales fiscalizadores $y$, sobre todo, a la rapidez con que efectuaran sus labores marineros, cargadores y remeros en la ardua tarea de movilizar las mercaderías (maderas).

Con todo, el tráfico marítimo de la bahía de Ancud densificó los intercambios y transacciones en el puerto al punto que favoreció intercambios con la población local. Es así como el auge exportador generó posibilidades para el comercio establecido de la ciudad o quienes llegaron a ella para vender artículos circunstancialmente requeridos por marineros, quienes como hemos establecido, tuvieron una presencia prolongada en la ribera de la ciudad. Este flujo no debe ser soslayado, aún más en los meses álgidos del flujo portuario -diciembre a marzo según el cuadro $\mathrm{N}^{\circ} 1$-.

Un caso excepcional se debió apreciar en el verano de 1854 cuando los registros aduaneros reportan el arribo de un contingente numeroso de barcos balleneros provenientes de Estados Unidos, Inglaterra y Francia. El "Lewis" y "Gustave" iniciaron la recalada de dichos barcos el 23 de enero, seguidos por el "Luiza" el día 29, "Abram Barker" el $1^{\circ}$ de febrero y el "San Jorge", "Nueva Granada" y "Esplendid" las siguientes dos semanas. Estas siete embarcaciones no solo elevaron la población flotante al sumar 237 tripulantes ${ }^{10}$ en una ciudad donde la población censada no alcanzaba los cinco mil habitantes,

9 AHN, Fondo Ministerio de Marina, Vol. 148, "Estado del movimiento marítimo que ha habido en el puerto de Ancud de la Provincia de Chiloé", $1^{\circ}$ octubre de 1857, s./f.

$10 \mathrm{ANH}$, Fondo Aduana de Chiloé, Vol. 81, leg. 2, docs. 73, 76, 78, 79, 83, 91, 92. sino que significaron una oportunidad interesante para estimular su vida económica al ser requeridas provisiones en los almacenes y vendedores situados a pocos pasos del muelle fiscal. Un impacto similar ocurría cuando llegaba una fragata militar en busca de provisiones o pertrechos para su tripulación, que mientras pernoctaba necesitaba de desayuno, almuerzo y cena fresca, o bien, en los casos más habituales en que los barcos ocupados en el transporte de maderas compraban su rancho. Esto último, por ejemplo, es lo que pudo aprovechar el comerciante chilote, Benito González, al embarcar en el "Luisa" previo a su salida a Caldera con sus diez tripulantes, 25 fanegas de papas, cinco docenas de gallinas y tres cajones de huevos ${ }^{11}$, lo cual también aprovechó Ventura Vidal al vender al capitán de la "Infatigable" cuatrocientos tarros de carne ( $\$ 4 \mathrm{c} / \mathrm{u}), 248$ panes ( $\$ 4$ cada 62 unidades), 16 almudes de papas (4 por 50 centavos) y 48 libras de legumbres (16 libras a 50 centavos) ${ }^{12}$.

Casos semejantes colocan en perspectiva algunas dinámicas económicas y sociales nuevas como consecuencia del auge exportador en la medida que se fue relevando la importancia citadina de Ancud respecto al conjunto de la provincia, pero sobre todo porque parte de su población rural encontró en ese dinamismo una alternativa para dar salida a sus propios artículos, con objeto no tanto de acumular como de satisfacer sus necesidades de subsistencia. Era el caso de aquellas familias que se trasladaban a través de bongos y lanchas cargando frutas, pescados o leche, es decir, productos básicamente con valor de uso, que llegaron al muelle fiscal con regularidad (León, 2015, p. 62) tal como lo hicieron ver en diversas ocasiones las autoridades en relación con quienes remontaban el río Pudeto y de lo cual dejó registro el médico europeo, Von Tschudi en 1838 cuando al anclar el "Edmond" se acercaron lanchas a ofrecer papas, pescado y agua a cambio de tabaco (Von Tschudi, 1842, p. 3), así como el viajero Carlos García Huidobro en 1864, quien anotó sobre su llegada a Ancud que bagaban [sic] varias embarcaciones pequeñas, muchas de ellas manejadas por mujeres (...) atracaban al

11 ANH, Fondo Aduana de Chiloé, Vol. 86, leg. 1, doc. 11, 21 de septiembre de 1855 , s/f.

12 ANH, Fondo Aduana de Chiloé, Vol. 85, leg. 3, doc. 9, 26 de marzo de 1855 , s./f. 
buque, subian cargadas de sus chiguas de ostras, con una jentileza admirable, para cambiarlas con los marineros por algunas bagatelas o frutas del norte (1864, p. 452).

\section{COMERCIANTES EXPORTADORES DE MADERA CHILOTA}

El flujo del puerto de Ancud se mantuvo en la década de 1850 porque existió una demanda extra-regional y además un grupo de comerciantes que lograron satisfacer esa demanda con regularidad, desarrollando una fluida comunicación con los puertos principales del país y la costa sur de Perú. Gracias a que en dicho puerto existió la única oficina de la Aduana de la provincia, todos los capitanes de barcos con dirección al norte debían registrarse allí para acceder a las pólizas que certificaban los cargamentos con que era posible descargar legalmente en los distintos muelles, dado que era necesarias para el cálculo de los derechos de faros, muelle y otros impuestos relacionados. Estas pólizas permiten establecer la carga, el destino y el barco que iba a servir de vehículo para la madera chilota pero de su análisis también es posible conocer quiénes participaron directamente en la exportación, en tanto cada comerciante debía pedir y firmar a título personal dicho documento con los oficiales fiscales. A partir de ello sabemos que 31 comerciantes o sociedades enviaron madera al norte el año 1855, una cifra que fue solo de veinte tres años más tarde.

La diferencia entre ambos años en el número de comerciantes respondía a los volúmenes limitados que aún presentaba el negocio exportador, permitiendo que tomaran participación algunos vecinos de Chiloé sin mediar grandes instalaciones ni redes de apoyo. En este sentido, en la década de 1850 aún no era posible asociar con un único nombre la exportación maderera como sucedió en los años finales del siglo y en el amanecer del siguiente con la mítica figura del Rey del Ciprés, nombre con que se hizo famoso Ciriaco Álvarez Vera en las inmediaciones de Chonchi, o cuando descolló la Sociedad Maderera de Quellón con establecimientos en el extremo sur de la isla grande (Bahamonde, 2004, pp. 31-35).

13 ANH, Fondo Aduana de Chiloé, Vol. 86, leg. 1, doc. 25, 24 de septiembre de 1855 , s./f.
Antes bien, el número de comerciantes pequeños como Francisco Cavada predominan entre los exportadores que pidieron pólizas de embarque con madera en 1855 y 1858. Éste en octubre de 1855 cargó al barco "Eclipse" de 135 toneladas 2.490 tablas aserradas, quinientos cuartones de 41/2 varas, mil cuartones de 4 varas, quinientas madrinas, cien viguetas, 2.158 tablones alerce, 23.000 tablas alerce y veinte mil rajas leña, además de 300 fanegas papas, 46 sacos de cebada $y$ en seis bultos distintos 120 piezas de jamón ${ }^{13}$. Del mismo modo, consiguió vender un segundo cargamento durante ese mismo año colocando en el "Africano" con dirección a Perú, quinientos guiones de vitola, 2.500 tablas aserradas, quinientos tijerales de 5 varas, quinientos tijerales de 6 varas, 2.200 cuartones de 41/2 varas, 206 viguetas de 8 varas, 290 tablones de alerce de 8 varas, cuatro mil tablones corrientes, ocho mil tablas de alerce, 250 madrinas de 4 varas, quinientos cuartones de 4 varas y veinte mil rajas de leña, a todo lo cual se sumaron 2.500 piezas de jamones ${ }^{14}$.

$\mathrm{Su}$ caso no era excepcional e ilustra a quienes participaron de la exportación de madera en una dimensión reducida, aquellos comerciantes intermitentes y que seguramente no tuvieron una red estable para vender madera, papas, jamones $u$ otros artículos, por lo que acaparaban mercaderías para vender una o dos veces al año a los capitanes de barcos que necesitaban completar su capacidad máxima de carga. Era el caso de Cavada, pero también de Benito González y Bautista Harriet en 1855 o de Pedro López, Rafael Araneda y Rudesindo Jofré en 1858. Todos los cuales no alcanzaron a desarrollar una actividad mercantil prolongada ni de magnitud suficiente para realizar embarques sostenidamente, quizá por lo mismo tampoco ha sido posible encontrar sus nombres en registros de muelles particulares o entre los apellidos habituales del municipio de Ancud, pese a que no es improbable que hayan participado de las juntas de vecinos del interior del archipiélago como en Chonchi, Quemchi o Achao.

Sobre dichos actores, de reducida capacidad exportadora, sin embargo, hubo un grupo de sociedades que capturaron para sí cuotas relevantes del negocio, aunque no por ello

14 ANH, Fondo Aduana de Chiloé, Vol. 86, leg. 2, doc. 58, 17 de octubre de 1855 , s./f. 
Tabla 2. Exportadores de maderas en el Puerto de Ancud 1855 y 1858.

\begin{tabular}{cccc}
\hline Nombres & envíos & Nombres & envíos \\
& 1855 & Mariano Lorca \& hermanos & 16 \\
\hline Andrade \& Velásquez & 11 & Juan Burr & 8 \\
Mariano Lorca \& & 9 & Antonio Andrade & 8 \\
Hermanos & 8 & Andrade \& Velásquez & 7 \\
Moreno \& González & 6 & Santiago Díaz & 7 \\
Juan Antonio Eusquiza & 5 & Juan de Dios Navarro y & 6 \\
Antonio Andrade & 5 & Enrique Wilner & 5 \\
Narciso Ruiz de Arce & 3 & Moreno \& González & 5 \\
Juan de Dios Navarro & 3 & Mancilla Velásquez & 3 \\
Santiago Díaz & 3 & Toribio Sánchez & 3 \\
\hline Andrade, Garrao \& Cía. & 87 & Total pólizas del año & 77 \\
\hline Total pólizas del año & & & \\
\hline
\end{tabular}

Fuente: ANH, Fondo Aduana de Chiloé, vols. 85, 86 y caja 3 y 4.

lograron integrar verticalmente la explotación con la comercialización o tuvieron opciones para forjar sociedades mercantiles con capacidad para controlar globalmente el mercado maderero fuera de las fronteras del archipiélago, las mismas que los habilitaran como actores protagónicos en el mercado extra-regional. A raíz de ello, existió un grupo principal pero igualmente subordinado en las redes comerciales, mostrándose con una débil capacidad para actuar a nivel provincial como motor transformador del paisaje y tradicionalismo del archipiélago. Con todo, constituyeron una suerte de alto comercio provincial del que se involucraron miembros de las familias más influyentes, las mismas que actuaban en forma permanente en instituciones relevantes a escala local como la municipalidad.

De acuerdo a la Tabla 2, en 1855 nueve comerciantes concentraban el $61 \%$ del total de pólizas halladas en los registro de la Aduana y en 1858 -coincidente con el número menor de ellos-, retuvieron el 82\% destacándose en el primer lugar la sociedad Andrade \& Velásquez y Mariano Lorca \& hermanos con el $13 \%$ y $21 \%$ del total de

15 ANH, Fondo Ministerio del Interior, Vol. 757, Oficios Recibidos de la Intendencia de Chiloé, 17 de noviembre de 1876 , s./f. Los antecedentes recopilados por el mismo Pedro Andrade para jubilarse de la administración, aclara permisos de embarque respectivamente.

En la sociedad Andrade \& Velásquez participó activamente Pedro Andrade, uno de los vecinos más prósperos e influyentes del archipiélago, fruto de su larga presencia como gobernador de Castro entre 1865 y $1876^{15}$, sede administrativa de la segunda ciudad más importante de la región y el distrito con mayor población de acuerdo a los registros censales de 1865 y 1875. Su papel protagónico estuvo sustentado en la propiedad de distintas balandras que circularon por el interior de la provincia, entre canales, islas del este y Guaitecas, que se dedicaron a transportar madera durante todo el año acumulando volúmenes sustantivos en la costa de Ancud, desde donde era embarcada a Valparaíso. A dicho puerto llegaron todos los envíos de la sociedad en 1855 y en 1858 cuatro de los siete barcos cargados, mientras los restantes se dirigieron más al norte: Arica, Cobija y Huasco.

El apellido Andrade también se incorporaba en otras sociedades comerciales influyentes como Andrade, Garrao \& Cía. que en 1855 embarcó maderas en otras tres naves y a través de Antonio Andrade, involucrado en el comercio maderero

que entre 1844 y 1851 fue profesor en distintas escuelas de Chiloé; y entre 1862 y 1876 fue tres años gobernador de Quinchao e inmediatamente después gobernador de Castro. 
especialmente con Perú cargando barcos en el sector de Balcacura, en lo que debió ser su centro de operaciones. De este modo, el clan Andrade fue responsable de un total de 16 pólizas con maderas en 1855 , un $22 \%$ del total de ese año por lo que puede considerarse uno de los grupos familiares más implicados y favorecidos de la expansión comercial del archipiélago.

En el año 1858 el lugar principal de Andrade \& Velásquez fue ocupado por la sociedad Mariano Lorca \& hermanos. Como se observa en el cuadro $\mathrm{N}^{\circ} 2$ su presencia estaba consolidada en 1855 al ser la segunda con más pólizas de embarque por lo que sus vinculaciones e infraestructura parecen haberse ampliado tres años más tarde, prácticamente doblando el número de barcos que cargaron desde Punta Arenas. Así, Mariano Lorca representaba uno de los más eximios miembros del comercio estableciendo una ruta de intercambio permanente entre Ancud y distintos puertos del norte del país, al tiempo que también se convertía en uno de los más pujantes importadores de artículos en la región. De las 16 pólizas madereras de 1858, una se dirigió a Iquique, Caldera y Cobija, tres a Valparaíso y cinco a los puertos de Coquimbo y Callao. Entre los cinco envío a Perú se contabilizaron por la Aduana algo más de 14 mil piezas de ciprés entre madrinas, cuartones y viguetas de distintos tamaños, mil lumas de 8 varas, 67.500 tablas y 15 mil tablones de alerce, además de 3.426 guiones de luma, 7.030 tijerales de muermo entre 4 y 6 varas de largo, 12.400 tablas aserradas y treinta mil rajas de leña, que fueron embarcadas en el muelle fiscal y Punta Arenas, un varadero de las inmediaciones de Ancud transformado en el centro de las operaciones mercantiles de la sociedad liderada por Mariano Lorca ${ }^{16}$.

Otra figura relevante del comercio maderero ancuditano fue Juan de Dios Navarro Sánchez, de quien ya hemos dado cuenta. Navarro en los años cincuenta habilitó bodegas y su muelle particular en las playas de Agüi en las inmediaciones de lo que había sido una de las plazas militares más importantes del archipiélago y que junto al fuerte de

16 Estas cifras se han extraído de la suma de las cinco pólizas ubicables en ANH, Fondo Aduana de Chiloé, Caja 3, leg. 1, doc. 34, 6 de abril de 1858, s./f.; Caja 4, leg. 1, doc. 27 y 29, 8 de septiembre y 3 de octubre de 1858, s./f.; leg. 2 , doc. 74,8 de octubre de 1858 , s./f. y; leg. 3, doc. 75, 20
San Antonio fueron efectivas defensas para que las primeras incursiones patriotas en Chiloé fueran un fracaso. Pero, esa relevancia se fue diluyendo con el paso de los años puesto que Agüi se transformó en el escenario ideal de los negocios mercantiles de uno de los miembros de la influente familia Navarro Sánchez.

Igual que Pedro Andrade, Juan de Dios Navarro tuvo su flota de balandras y barcos, entre las cuales se destacaron la "Clorinda", "Carmen Dolores" y en los años sesenta el barco de origen guatemalteco "Milagro", al menos hasta 1870 , fecha en que se hundió en las costas del río Toltén ${ }^{17}$. La "Carmen Dolores" era en realidad el barco inglés "Isabella" que hizo ruta en diversas ocasiones por los puertos de Chile y California, según lo ha registrado en un detenido estudio Claudio Véliz (1961), por lo cual entregaba opciones inmejorables a su propietario para realizar rutas de larga distancia por la costa del Pacífico. Estas opciones debieron motivar suficientemente a Navarro para que la adquiriera en un remate en 1855, luego que llevando guano a Europa recalara en la bahía de Ancud por averías sufridas en alta mar por causa de malos tiempos ${ }^{18}$.

Esta embarcación de origen inglés tenía una capacidad de 170 toneladas, situándose muy por encima de las balandras y goletas construidas en el interior del archipiélago que promediaban capacidades de cincuenta o sesenta, aunque tampoco alcanzaba a superar embarcaciones regulares en Ancud superiores a 350 o 450 toneladas. A través de la "Carmen Dolores", Navarro tuvo en sus manos un adelanto importante para su actividad comercial, encontrando en su tonelaje una vía expedita para trabar relaciones con distintos puertos, a los cuales también se dedicaron otros miembros de su familia como Silvio y Toribio Sánchez al disponer regularmente del barco "Dolores" de capacidad de 250 toneladas y con flujo recurrente a Perú (Callao).

El capitán Rafael González junto a su tripulación de diez $\mathrm{u}$ once marineros hizo cinco viajes en 1858 con la "Carmen Dolores" cubriendo

de agosto de 1858, s./f.

17 ANH, Ministerio de Marina, Vol. 256, No. 127, 15 de octubre de 1870, s./f.

18 ANH, Fondo Aduana de Chiloé, Vol. 86, $4^{\text {to }}$ trimestre, leg. 1 , doc. 16,4 de octubre de 1855 , s./f. 
la ruta Ancud-Coquimbo en cuatro ocasiones y una entre la primera y Valparaíso. Como se observó en relación al clan Andrade, los viajes de la "Carmen Dolores" transportaron en forma predominante maderas nativas ${ }^{19}$, que en un solo cargamento transportó 35.000 tablas de alerce, dos mil cuartones de ciprés de $4^{1 / 2}$ varas, trescientos tijerales de 6 varas, dos mil tablas aserradas de 4 varas, quinientas madrinas de ciprés de 4 varas, cuatrocientas viguetas de 8 varas ciprés i alerce, cincuenta vigas de cuchillo de 8 y 9 varas así como treinta mil rajas de leña, que dicho sea de paso, eran utilizadas básicamente como combustible en la época ${ }^{20}$.

Las cantidades de madera embarcadas tanto por Mariano Lorca como por Juan de Dios Navarro Sánchez, considerados en singular, permiten ponderar las dimensiones alcanzadas por el negocio maderero a falta de una estadística regular y minuciosa -que naturalmente aún queda por construir- sobre la exportación de dicho recurso por la provincia de Chiloé durante el siglo XIX. Si bien es cierto las magnitudes del negocio siguieron siendo reducidas con claridad eran mayores a los registros existentes para fines del siglo XVIII. Esto es lo que se puede establecer de las cifras comentadas por la historiadora María Ximena Urbina al seguir la obra de José Moraleda, quien calculaba en 200.000 las tablas de alerce exportadas por el conjunto de la provincia al Perú (Urbina, 2011, p. 60), cifra semejante a lo indicado por el capitán inglés Blanckley (1834), cuando calcula una exportación cercana a 260.000 tablas por año (p. 352-3). Ambos casos aluden específicamente al comercio de tablas de alerce, artículo que Mariano Loca en 1858 embarcó en una cantidad estimada de 67.500 por sí solo desde Ancud, seguido en ese año por el comerciante local Juan de Dios Navarro quien exportó otras 35 mil tablas de alerce. Es decir,

19 Aunque predominaron las maderas es interesante anotar que la "Carmen Dolores" también exportó suelas dando oportuna salida a la producción de curtiembres que controlaba la familia Navarro en el sector de Lechagua, el único establecimiento del rubro operativo en la década de 1850 y que debió tener una prolongada existencia porque en las matrículas comerciales del Departamento de Ancud en fecha tardía de 1887 aún figuraba como parte de las actividades de José Daniel Sánchez en la hacia mediados del siglo XIX hubo un aumento global en la explotación de los bosques chilotes $y$, posiblemente, un avance en el modo en que eran organizadas las expediciones, el transporte de la madera a lo largo y ancho de la región o la forma en que eran manufacturadas y dimensionadas.

Sobre este punto, la figura de Juan Burr es de sumo interés ya que fue uno de los comerciantes que experimentó un mayor aumento en el número de pólizas de embarque de maderas pasando una a ocho entre 1855 y 1858 . Esto da cuenta de una vertiginosa labor mercantil, que significó una ampliación de sus actividades más habituales relacionadas con la transacción regular con los buques norteamericanos que ingresaban al archipiélago, tarea en la cual Burr, junto a su padre, Roberto Dimsadall, se ocuparon casi exclusivamente al actuar como consignatarios y compradores de sal, aceite y otros productos provenientes del exterior (Vásquez de Acuña, 1985).

Juan Burr tuvo también su propio muelle y bodegas en las cercanías del muelle fiscal, pero se destacó más por ser uno de los pocos comerciantes que en sus pólizas distinguía las maderas aserradas "a brazo" de aquellas "a máquina". De acuerdo con Isidro Vásquez de Acuña, su padre fue el primero que instaló un aserradero hidráulico en la costa pacífico, el cual importó directamente desde Estados Unidos, el mismo que renovó en 1839 gracias al envío desde Nueva York por parte de la casa Hussey \& Macray de nuevas instalaciones y repuestos (1985, p. 80).

La diferenciación entre maderas aserradas a "brazo" y "máquina" mostraba que en la década de 1850 ya existían algunas innovaciones en las formas de trabajo que predominaban en la provincia. Hacia 1858 también contribuyó en ello Manuel Mancilla Velásquez, pues en el mes de octubre recibía desde Paita, Perú, una máquina

misma localidad y a pocos pasos de la destilería de aguardiente que tenía inscrita Narciso Sánchez en igual año. Del mismo modo, el periódico El Chilote informaba en su edición del 4 de enero de 1873 que eran dos las curtiembres en funcionamiento en Ancud (la otra pertenecía a Leopoldo Kowoll) y que ambas compraban "todos" los cueros de la provincia.

20 ANH, Fondo Aduana de Chiloé, Caja 3, leg. 1, doc. 82, 2 de marzo de 1858, s./f. 
de aserrar madera i moler trigo usada y libre de derecho de importación ${ }^{21}$ avaluada en doscientos pesos. Modalidad que presumiblemente también incorporó el comerciante Mariano Lorca pues en todos sus envíos a Perú en 1858 incluía tablas aserradas las cuales sumaron cerca de 12.400 ese año, que a la sazón eran valoradas a 14 pesos el ciento puestas en el muelle fiscal.

De acuerdo a esto, Juan Burr y otros miembros responsables del alto comercio desde Ancud tenían instalados aserraderos con objeto de asegurar la calidad de las maderas exportadas, y así estandarizar el dimensionado de los embarques y optimizar su calidad. El problema era que al situarse lejos de los puntos de explotación, en definitiva eran insuficientes para hacerse cargo de la totalidad del comercio maderero existente por lo que no lograban evitar que los envíos hacia los puertos del norte del país mezclaran tablas aserradas por las pocas máquinas ancuditanas con la madera dimensionada más rudimentariamente en el interior de la región.

Por este motivo el dimensionado y labrado de las maderas se constituyó en el problema crucial para el comercio chilote a contar de los años cincuenta del siglo XIX. Tarea impostergable según observadores privilegiados de la realidad chilota como lo era el intendente José Rondizzoni (1854), para quien la calidad de los cortes de la madera iba permitir que se prolongara o disminuyera el interés del mercado extra-regional por la producción local. Y, fue lo que precisamente no habría podido resolverse en el mediano plazo. En la década de 1860 el alto comercio situado en Ancud no desarrolló la infraestructura necesaria para uniformar la producción como sí lo hicieron, utilizando la misma población chilota como jornalera, los comerciantes madereros de los distritos de Llanquihue, en torno a las localidades de Calbuco y Puerto Montt. Lugares donde se fueron fortaleciendo las competencias industriales de los aserraderos manteniendo una alta calidad de los artículos madereros que exportaron. De allí, entonces, que el auge comercial de Ancud y de la Isla Grande se deteriorara al finalizar la década de 1860 , momento en que la prensa, autoridades políticas y los representantes del comercio concordaban en que ya no tenían posibilidades para competir y retener un tráfico marítimo ávido de recursos forestales, marcando el declive de Ancud como puerto principal del comercio de Chiloé y uno de los más importantes del sur de Chile.

\section{ASOCIACIÓN FAMILIAR Y COMPARTIMENTACIÓN DEL COMERCIO}

El seguimiento de la trayectoria de algunos comerciantes influyentes de la plaza de Ancud como se ha esbozado hasta acá, puede llevar al equívoco de que premunidos de muelles, barcos o balandras, cada comerciantes estaba lanzado a una competencia por acopiar y embarcar madera, en circunstancia que los barcos provenientes del norte llegaban "libremente" para comprar rápidamente recursos forestales de Chiloé. Esta imagen típica de zonas de frontera económica donde el asentamiento de la población y sus instituciones aún no logra consolidarse ni echar raíces (como fars west) es algo que pudo ocurrir pero en las zonas distantes a Ancud. Sobre todo en los puntos de explotación del alerce y ciprés, realizada en Chiloé continental e islas Guaitecas, lugares que al carecer de instituciones politicas, determinaba que las cuadrillas de peones y hacheros quedaban libres en los bosques, sin más remedio de solución de sus conflictos las solidaridades propias que colocaran en juego durante las faenas de trabajo.

Contra esa imagen caótica el argumento que hemos deslizado ha colocado de relieve la estabilidad y regularidad de los intercambios portuarios y la presencia de destacados mercaderes en la ciudad de Ancud. Donde el tráfico estaba regulado y constreñido a las relaciones tradicionales de una élite históricamente atada a la provincia austral, siendo los apellidos Sánchez, Navarro y Andrade parte de antiguos e influyentes linajes de la región. De este modo, antes de competir unos con otros para conseguir compradores, se vislumbra que los comerciantes madereros más importantes del archipiélago convivieron y colaboraron durante la expansión exportadora, al punto que llegaron a estipular normas de buenas prácticas en 1855 y 1857 para evitar embarcar maderas irregulares, de escaso tamaño o diferentes calidades (Morales, 
2014, pp. 49-50). Es posiblemente por esto que dichos comerciantes fueron poco propensos a innovar en sus estrategias económicas y si bien respondieron al aumento de la demanda, no lograron proyectar en el tiempo sus actividades capturando en el largo plazo los mercados del centro y norte del país.

Parte de esa estabilidad se explica por el carácter cerrado de las relaciones familiares que los principales comerciantes desarrollaron, coincidiendo con los patrones tradicionales de las élites agrícolas. Las que a través del establecimiento de relaciones solidarias horizontales como el compadrazgo y el matrimonio, en el conjunto de Latinoamérica española y portuguesa, lograron una exitosa reproducción (Langue, 2000, pp. 104-5), preservando el patrimonio, influencias y poder simbólico en sus respectivas comunidades, donde predominaban históricamente tal como lo advierten Isabel Moll y Pere Salas (2002) en relación a sectores agrícolas españoles en el siglo XIX.

Algo de esto se puede percibir en Chiloé, donde el padre Luis de Mansilla armado de un sesgo conservador de cuño decimonónico, advertía que una singular tradición de los españoles en la región los mantuvo virtualmente separados del mundo indígena, puesto que desarrollando una vida común sin "sobresaltos" (Mansilla, 1911, p. 3) desecharon vincularse directamente con la población aborigen. Rasgo que es confirmado por Aureliano Oyarzún cuando señala que no eran habituales los matrimonios entre españoles e indígenas en el siglo XVIII (Oyarzún, 1935, p. 9). Frente a ello, puede interesar, en la misma perspectiva, la trayectoria de Roberto Dimsdall Bur ligado, no obstante ser extranjero, a una de las familias influyentes de la provincia gracias a que contrajo matrimonio con Cristina Navarro Sánchez, hermana de Juan de Dios Navarro.

Roberto, nació en 1804 en la localidad norteamericana de Burlington y antes de llegar a Chiloé en 1828 hizo viajes de negocios por la costa sur de Brasil y Montevideo (Vásquez de Acuña, 1985, pp. 75-81). De acuerdo a una reseña biográfica publicada en El Imparcial de Chiloé el 10 de octubre de 1885 tras conocerse su deceso, Roberto habría observado las potencialidades económicas del archipiélago en la medida que era posible el espendio de tablas bien preparadas y de otras maderas abundantes en el sur de Chile podia ser un negocio mui lucrativo, decidiéndose radicar en Chiloé cuando despuntaba el período republicano. Para esa misma época decide instalar el primer aserradero hidráulico de Sudamérica en las cercanías de Dalcahue, una máquina que, según la misma nota periodística, fue mirada por los naturales con suma desconfianza, hasta el punto de destruir el estanque y quemar la casa (p. 1). Para Daniel Quiroz, además de esa actividad, Roberto Burr aprovechó el hecho de ser uno de los pocos extranjeros en la isla y durante varias décadas fue agente Pacific Mail Steamship Company comprando aceite y sal (Quiróz, 2010, p. 4), productos que luego eran introducidos en la provincia o comercializados a Valdivia y Río Bueno.

Con esa prolífica actividad Roberto Burr pudo integrarse al circuito más privilegiado de los vecinos de Chiloé, pero al contraer nupcias con Cristina Navarro en la década de 1830, debió ampliar el margen de sus relaciones al quedar habilitado directamente en uno de los clanes familiares más destacados de la región. Enlace que no acabó allí pues se intensificaría en lo sucesivo, ya que sus hijos (4 mujeres y 4 hombres) igual contrajeron nupcias con importantes familias incluyendo a miembros de la familia Sánchez y Andrade. De hecho, uno de los hijos del matrimonio de Roberto y Cristina, Juan, contrajo nupcias con con Rosalia Navarro, una de sus primas (Cavada, 1934, p. 156).

Estas relaciones de parentesco y la intensificación de los vínculos entre las familias dedicadas al alto comercio, debieron incidir en el hecho de que existiera una baja propensión a la competencia mercantil en la década de 1850 . De este modo, es posible percibir una incipiente compartimentación o distribución razonable de la exportación, pues cada sociedad mercantil se fue especializando en abastecer preferentemente una parte del mercado disponible.

Valparaíso era un paso obligado para todos los comerciantes ya que se transformó en el puerto donde se cargaba la mayor parte las mercaderías internadas en el archipiélago. Por esta razón, el alto comercio de Chiloé, además de vender madera, era el responsable del abastecimiento de la población local, para lo cual formaron las tiendas "al mayor" de la provincia. Todos ellos surtieron sus almacenes 
o bodegas desde Valparaíso, desembarcando en Ancud artículos de primera necesidad como la harina, azúcar, charqui, frejoles o fideos, o bien el agua ardiente y vino, productos a los que se sumaban telas y el vestuario con que reemplazarían los trajes tradicionales de la región, así como los implementos domésticos que lentamente debieron comenzar a dar diversidad a cada villa o aldea rural en la medida que desde Ancud circularon hacia el interior cuchillería, loza, vasos o las cotizadas ollas estañadas, tan necesarias para los fogones. A ello se podría agregar un inacabable listado de artículos, suntuarios o no, como las velas (para iluminación y géneros para navegar), hilos, agujas, espejos, serruchos, pintura o las hachas requeridas por los maestros o carpinteros así como por la población ocupada en las faenas de corte y dimensionado de la madera.

Sin embargo Valparaíso no era el centro de las operaciones mercantiles para todos los comerciantes madereros. Si bien todos compraban mercaderías en las bodegas de dicho puerto preferentemente al momento de vender establecieron contactos diferenciados. La sociedad de Andrade \& Velásquez hizo sus once envíos de maderas directamente a Valparaíso en cuatro embarcaciones distintas a lo largo de 1855. Pero la sociedad Mariano Lorca \& hermanos completó carga solo tres veces a dicho puerto, trasladando sus maderas en forma preferente al norte. En cinco ocasiones al Callao con los barcos "Teresa Terri", "Nueva Isabel", "Holiwood", "Guimaraens" y "Concordia"; en cinco oportunidades a Coquimbo por medio de los barcos "Martina Oresqui", "María" y el ya mencionado "Guimaraens"; y una vez a Cobija (Bolivia), Caldera e Iquique en 1855.

Aún más marginales fueron los contactos de Juan Burr en 1858 con Valparaíso, destinando sus envíos a Bolivia (Cobija) y Caldera, diferenciándose en ese año al clan Andrade que a través de la sociedad Andrade \& Velásquez, Andrade, Garrao \& Cía, o en las personas de Antonio y José Andrade, colocaron los mayores envíos de maderas en el puerto mayor del país. Para lo cual utilizaron en reiteradas ocasiones el barco nacional "José Guimaraens" con capacidad cercana de 290 toneladas.

Esta suerte de distribución geográfica o zonas de influencia comercial, debe ser abordada con mayor profundidad y proyección cronológica para establecer conclusiones definitivas, pero es interesante que fuera Juan Burr el mayor exportador de fanegas de papas a Lota y Talcahuano en 1858, o que Mariano Lorca se transformara en uno de los principales abastecedores de maderas chilota en el Callao y Coquimbo y, en relación a la internación de mercaderías, se transformara en un importador frecuente de artículos beneficiándose de que Carlos, uno de sus hermanos, residía en Valparaíso, lugar privilegiado para efectuar envíos continuos a Chiloé.

Con todo, la estabilidad de los lazos comerciales que disfrutó el alto comercio dedicado a la exportación de maderas y su distribución regional del mercado existente en la década de 1850 , entregaron regularidad y certidumbre de sus actividades mercantiles en el interior de la provincia. Al conocer con anterioridad que iban a tener compradores, tuvieron suficiente seguridad para realizar transacciones a lo largo de todo el año e iniciar pactos con la población rural y campesina para que se dispusiera a explotar los bosques a brazo y hacha. La suma de esa certidumbre y la predisposición a inhibir una competencia directa dado sus lazos de parentesco, hizo que los comerciantes principales de Chiloé no se vieran comprometidos a establecer una organización racional de la explotación forestal ni desarrollaran inversiones en el mediano plazo, proporcionando infraestructura y maquinarias para efectuar un trabajo más eficiente. De tal suerte, los apellidos Andrade, Sánchez, Navarro, Burr u otros representantes del alto comercio isleño quedaron satisfechos con mantener el trabajo tradicional de la población chilota y distribuirse o integrar sus intereses mercantiles inhibiendo una competencia que los llevara a realizar cambios sustantivos en el mercadeo regional.

\section{COMENTARIOS FINALES}

El dinamismo de la actividad comercial de Ancud a mediados del siglo XIX contrastó con la parsimoniosa vida agraria de los habitantes en los distritos rurales del archipiélago. Los habitantes de la ciudad intensificaron sus contactos con marineros y capitanes de barco, que dado el número considerable de las embarcaciones, debió 
ser uno de los primeros síntomas de la modernidad para muchos chilotes, aunque ella no alcanzó para generar una dinámica transformadora duradera. Una parte importante de los observadores sobre la región indican que para fines del siglo XIX el paisaje rural y la fisonomía de sus poblaciones había experimentado pocos cambios en comparación, por ejemplo, a la industriosa región de Llanquihue.

Una de las razones más probable del limitado impulso transformador que tuvo la actividad comercial pese a su inusitado movimiento en la década de 1850 se encuentra fuera de la región. La madera era un recurso necesario y fundamental para la expansión económica que se experimentaba en el norte minero y en el sector de la construcción y obras públicas en general -especialmente en la extensión de las redes ferroviarias por los requerimientos de durmientes-, pero tampoco era un recurso altamente cotizado en el mercado. Por lo mismo en su extracción y comercialización se marginaron los principales agentes económicos de la época, a quienes no les debió parecer suficientemente atractivo involucrarse directamente en la explotación maderera en los confines de la región chilota. Es sintomático de ello el hecho que la madera a lo largo de la década de 1850 no experimentó variaciones sustantivas de sus valores y se transara rígidamente en el muelle fiscal de Ancud a pesar del mayor interés de los mercados del norte y centro del país. Esto es algo que aún queda por establecer con una base documental sustantiva y prolongada en el tiempo, pero bástenos por el momento señalar que en los registros aduaneros el ciento de tablas de alerce tuvo un valor de 6,25 en 1853, el mismo que se pagaba diez años más tarde, situación idéntica ocurre con los tablones de alerce al ser transados en 12,5 pesos ambos años y respecto a los cuartones de madera ciprés, intercambiados en el mismo precio en 1853 y 1863.

No obstante la baja cotización en el mercado alcanzada por la madera, no puede esconderse el hecho que los comerciantes chilotes participaron activamente de su mercadeo a nivel nacional. Quienes articularon a nivel provincial la exportación, actuando como compradores de madera en el interior del archipiélago y como exportadores directos con sus propios barcos, aprovecharon el grueso del negocio pero en el corto plazo. Alli el dilema. Si bien los comerciantes de la plaza de Ancud tuvieron éxito y fueron eficaces abastecedores de recuerdos forestales, se mostraron menos competentes para consolidar su actividad mercantil cuando comenzaron a competir con nuevos actores en el mercado regional, en particular con los aserraderos de Llanquihue. Es cierto que el lapso de tiempo fue breve -no más allá de veinte años entre 1850 y 1870- pero no menos lo es que su desempeño como habilitadores antes que explotadores de los bosques implicó que los trabajadores madereros se surtieran únicamente de sus experiencias tradicionales para efectuar las tareas de corte y dimensionado de las tablas, cuartones y madrinas. En este caso, su papel de mercaderes confabuló con la necesaria innovación y racionalización del trabajo maderero en los innumerables nichos boscosos del archipiélago.

Esto no quiere decir que los miembros del alto comercio maderero de la provincia hicieron poco y nada para abastecer con maderas puertos como Caldera, Coquimbo y Valparaíso y más lejanos aún, Paita o Callao. Como hemos podido señalar algunos de ellos adquirieron barcos y construyeron o habilitaron puertos, mientras que otros ampliaron o crearon sus propios aserraderos. Del mismo modo, junto con gestionar sus relaciones con el centro y norte del país, requirieron de la población rural masculina de la provincia para ocuparla en la explotación y transporte de las maderas nativas, razón por la que debieron habilitarla con alimentos, herramientas de trabajo (hachas) y obviamente con las balandras necesarias para surcar los canales de la región. Todo esto era algo complejo para efectos de abordar la magnitud del negocio exportador. El dilema es que antes de alterar los usos y las costumbres optaron por prolongarlas en los nuevos distritos forestales que se fueron abriendo a la explotación, demostrándose débiles para retener el mercado aunque exitosos para mantenerse como grupo privilegiado en la provincia. No puede pasar desapercibido que el mismo Juan de Dios Navarro se transformó en parlamentario por los departamentos de Ancud y Quinchao entre 1876 y 1882, con lo cual se abre una dimensión aún inexplorada en relación a los comerciantes madereros de Chiloé relacionada con los medios y los usos del poder político que ostentaron en la región durante todo el siglo XIX. 


\section{BIBLIOGRAFÍA}

Fuentes primarias

Archivo Nacional Histórico (ANH), Fondo Ministerio de Marina. Archivo Nacional Histórico (ANH), Fondo Aduana de Chiloé. Archivo Nacional Histórico (ANH), Fondo Ministerio del Interior.

Fuentes periódicas

El Chilote, de Ancud (1868-1886).

El Imparcial, de Ancud (1885-1886).

Fuentes impresas

Blanckley, C. (1834). Account of the Island and Province of Chiloé. Journal of the Royal Geographical Society of London, 4, 344-361.

De Beranger, C. (1893). Relacion jeográfica de la Provincia de Chiloé. Santiago, Imprenta Cervantes.

García Huidobro, C. (1864). Provincias meridionales de Chile. $\mathrm{Su}$ descripcion segun un viaje hecho a ellos por don Carlos García Huidobro. Anales 25(2), 439-489.

Rondizzoni, J. (1854). Memoria Que el Intendente de Chiloé presenta al señor Ministro de Estado en el Departamento del Interior, dando cuenta de todos los ramos de la Administración. Ancud, 10 de mayo de 1854.

Weber, A. (1903). Chiloé: su estado actual, su colonización, su porvenir. Santiago, Imprenta Mejía.

Fuentes secundarias

Bahamonde, J. (2004). Historia de Quellón (1900-1960): Información administrativa, industrial, social $y$ cultural de la comuna. Talcahuano: Ed. Trama Ediciones.

Cariola, C., \& Sunkel, O. (1990). La historia económica de Chile, 1830 y 1930: dos ensayos y una bibliografía. Madrid: Eds. Cultura Hispánica del Instituto de Cooperación Iberoamericana.

Carreño, G., \& Espinoza, A. (2013). "El arpón se queda en la familia. La ballenera Mayaca en el Golfo de Arauco". En Knoller, D`Ambrosio et al. Povos e coletivos pesqueiros. Estudos etnográficos e perspectivas socioantropológicas sobre o viver e o trabalhar. Brasil, Editora da furg.

Cavada, F. (1934). Apuntes biográficos de personas y familias de Chiloé insular. Santiago, Nascimento.
Cavieres, E. (1988). Comercio chileno y comerciantes ingleses 1820-1880: (un ciclo de historia económica). Valparaíso: Universidad Católica de Valparaíso-Instituto de Historia.

Fischer, R. (1987). Ancud y el desarrollo de sus espacios sociales. Revista Chiloé, 8, 39-44.

Fradkin, R. (2006). Caminos abiertos en la pampa. Dos décadas de renovación de la historia rural rioplatense desde mediados del siglo XVIII a mediados del XIX. En Jorge Gelman (comp.) La historia económica argentina en la encrucijada. Balances y perspectivas (189207). Buenos Aires: Asociación Argentina de Historia Económica/Prometeo.

Garavaglia, J. C., \& Gelman J. (1998). Mucha tierra y poca gente: un nuevo balance historiográfico de la historia rural platense (1750-1850). Historia agraria, 15, 2950.

Garrido, E., Castagneto, G., Rivera, E., \& Mesina, V. (2006). Historia de la marina mercante chilena 1541-2006. Valparaíso: Asociación Nacional de Armadores de Chile.

Guerra, Francois-Xavier (2000). El análisis de los grupos sociales: balance historiográfico y debate crítico. Anuario del Instituto de Estudios Histórico-Sociales, 15, 117-122.

Langue, F. (2000). Las élites en América española. De la historia de las prácticas a las prácticas de la historia. Anuario del Instituto de Estudios Histórico-Sociales, 15, 101-116.

León, M. (2004). La vida Económica de un mundo insular: Una caracterización de Chiloé en el siglo XIX. Revista Cultura de y desde Chiloé, 18, 55-78.

León, M. (2015). Una provincia "enteramente insular": Geografía, exploraciones y cotidianeidad en Chiloé Republicano, Chile (1826-1900). Magallania, 43(1), 53-68.

Mansilla, V. L. (1911). Relación Genealógica de varias familias de Chiloé. Ancud: Imprenta El Colono.

Martinic, M. 2004. De la trapanada al Áysen. Una mirada reflexiva sobre el acontecer de la región de Aysén desde la Prehistoria hasta nuestros días. Santiago: Pehuén.

Moll, I., \& Salas, P. (2002). Las pequeñas élites agrarias y su participación durante la vida política durante la segunda mitad del siglo XIX. Ayer, 48, 159-183.

Moraga, P. (1992). Chiloé: condiciones económicas y comercio (1850-1900). Tesis Licenciatura, Pontificia Universidad Católica de Chile, Santiago.

Morales, D. (2014). El negocio de la madera: comerciantes y 
"hacheros" de Chiloé, 1850-1875. Magallanía, 42(2), 41-60.

Ortega, L. (2005). Chile en ruta al capitalismo: cambio, euforia y depresión (1850-1880). Santiago: LomDibam.

Oyarzún, A. (1935). Cultura aborigen de Chiloé. Santiago: Imprenta Universitaria.

Quiroz, D. (2010). La caza de ballenas en las aguas de Chiloé durante los siglos XIX y XX". II Seminario "Chiloé: Historia del contacto. Ancud: DIBAM-Museo Regional de Ancud. Consultado el 10 de junio 2015 en: http://www. dibam.cl/Recursos/Contenidos/De\%20Ancud/archivos/ LA\%20CAZA\%20DE\%20BALLENAS\%20EN\%20 LAS\%20AGUAS\%20DE\%20CHILO\%C3\%89.pdf

Torrejón, F., Cisternas, M., Alvial, I., \& Torres, L. (2011). Consecuencias de la tala maderera colonial en los bosques de alerce de Chiloé, sur de Chile (siglos XVI-
XIX). Magallanía, 39(2), 75-95.

Urbina, M. X. (2011). Análisis histórico-cultural del alerce en la Patagonia septentrional occidental, Chiloé, siglos XVIXIX. Magallania, 39(2), 57-73.

Urbina, R. (2009). El modo de comerciar de los chilotes a fines del siglo XVIII. Revista Cultura de y desde Chiloé, 23, 65-95.

Urbina, R. (1983). La periferia meridional indiana: Chiloé en el siglo XVIII. Valparaíso: Universitaria.

Vásquez De Acuña, I. (1985). La familia Burr. Revista de Estudios Históricos, XXVIII, 30, 15-142.

Véliz, C. (1961). Historia de la marina mercante de Chile. Santiago: Editorial Universitaria.

Villalobos, S. (1968). El comercio y la crisis colonial. Un mito de la Independencia. Santiago: Editorial Universitaria.

Von Tschudi, J. J. (1842). Travels in Peru. Nueva York: A.S. Bames \& Co. 
